\title{
Adsorbability Enhancement of Macroporous Resin by Dielectric Barrier Discharge Plasma Treatment to Phenol in Water
}

\author{
Shoufeng Tang, Deling Yuan, and Jun He \\ Key Laboratory of Applied Chemistry, School of Environmental and Chemical Engineering, Yanshan University, \\ Qinhuangdao 066004, China \\ Correspondence should be addressed to Deling Yuan; yuandeling83@126.com
}

Received 22 July 2016; Revised 2 October 2016; Accepted 9 October 2016

Academic Editor: Reyna Natividad

Copyright (C) 2016 Shoufeng Tang et al. This is an open access article distributed under the Creative Commons Attribution License, which permits unrestricted use, distribution, and reproduction in any medium, provided the original work is properly cited.

In order to enhance the adsorption efficiency and economize the use of macroporous resin, we have treated it with the dielectric barrier discharge (DBD) plasma to improve its adsorbing capacity for phenol. The effects of operation conditions, for instance, applied voltage, treated time, and air flow rate on resin, were investigated by adsorption kinetics and isotherms. Results showed that the adsorption data were in good agreement with the pseudo-second-order and Freundlich equation. Experimental results showed that the modified resin was $156.5 \mathrm{mg} / \mathrm{g}$ and $39.2 \%$ higher than the untreated sample, when the modified conditions were conducted for discharge voltage $20 \mathrm{kV}$, treatment time $45 \mathrm{~min}$, and air flow rate $1.2 \mathrm{~L} / \mathrm{min}$. The resin was characterized by FTIR and nitrogen adsorption isotherms before and after the DBD processes. It was found that the reason for the enhancement of resin adsorbability was attributed to the DBD plasma changing the surface physical and chemical structure.

\section{Introduction}

Adsorption on resin is a simple technology that has found widespread application in the treatment of industrial effluents $[1,2]$. In order to improve the adsorption efficiency and economize the use of macroporous resins, many studies on surface modifications have been carried out, and they mainly focus on chemical modifications [3-6].

Recently, nonthermal plasma technology for material modification becomes one of the most active fields [7-9]. Nonthermal plasma surface treatment has lots of features, including no change to the thermal and mechanical properties of the adsorbents, but altering the various interfacial characteristics, such as the surface chemical and physical structure properties $[10,11]$.

Dielectric barrier discharge (DBD) could produce spatially uniform and stable plasma under atmospheric pressure easily $[12,13]$. Using oxygen as gas source in DBD plasma, various kinds of active species including high-energy electron, ozone, and many other strong oxidized free radicals have been generated $[12,13]$, which could be beneficial to the material surface modification. However, to our knowledge, systematic studies on surface modification of resin by DBD plasma are still limited.

Phenol is a kind of highly toxic and refractory pollutant commonly emitted from industrial effluents. This paper presents a new approach that macroporous resin is modified in a double dielectric barriers discharge reactor. The effects of operation parameters for phenol removal, including applied voltage, treatment time, and gas flow rate on adsorption kinetics and adsorption isotherms, have been investigated. FTIR and $\mathrm{N}_{2}$ adsorption isotherms were employed to evaluate the surface chemical and physical characteristics of macroporous resin treated with DBD plasma. The obtained experimental data demonstrate the DBD could enhance the phenol adsorption of resin effectively.

\section{Experimental}

2.1. Materials. Macroporous resin (XDA-1, diameter 0.3$1.2 \mathrm{~mm}$ ) was acquired from Xian Sunresin and Technology Co. Ltd. (Shanxi province, China). Before adsorption, the resins were under extraction filtration process using ethanol for at least 8 hours and then dried in an oven at $333 \mathrm{~K}$ 


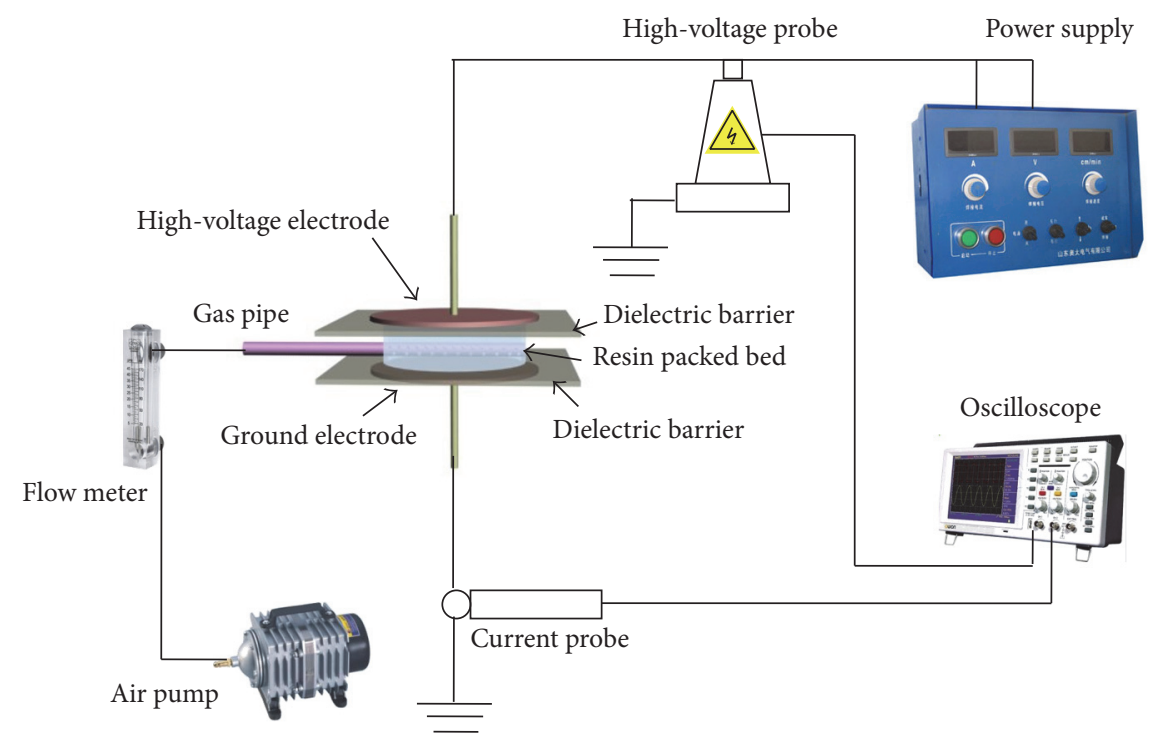

FIGURE 1: Schematics of the experimental system.

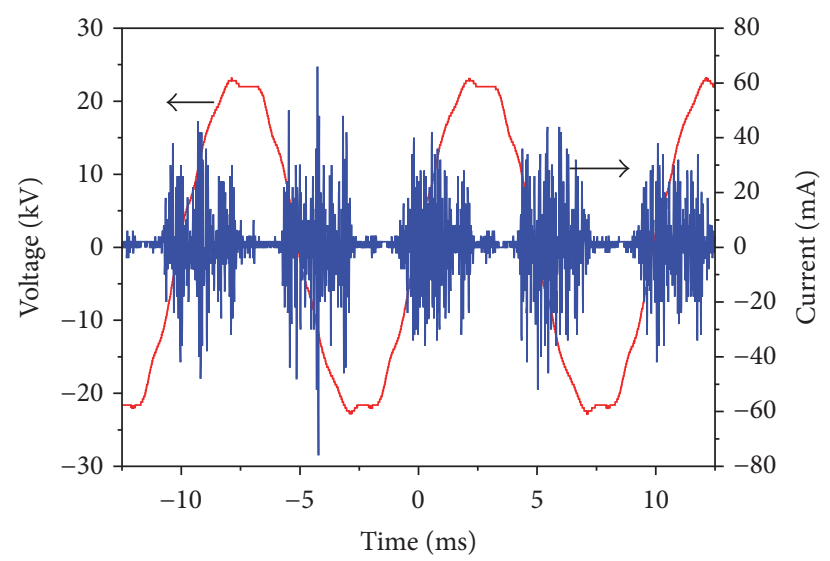

FIgURE 2: Typical voltage and current waveforms of the DBD reactor.

overnight. Phenol and other chemical reagents were of analytical grade and purchased from the Tianjin Kermel Co., Ltd. (Tianjin, China). The phenol solution was prepared with deionized water.

2.2. Experimental System. Figure 1 illustrated the DBD treatment system. The DBD reactor was driven by an alternating current (AC) high-voltage power. The reactor was comprised of two parallel-plate stainless steel electrodes as the high-voltage and ground electrodes, respectively, and each electrode was covered by one quartz glass dielectric, and the detailed dimensions were given in our previous articles [14]. The AC power frequency was $100 \mathrm{~Hz}$, and the peak voltage was adjustable in a range of $0-50 \mathrm{kV}$. In every batch experiment, before the DBD treatment began, $2.0 \mathrm{~g}$ resin was filled in the packed bed of the reactor. Typical voltage and current waveforms of the DBD reactor were shown in Figure 2, which were recorded by a digital oscilloscope
(Tektronix TDS2014, USA) equipped with a voltage probe (Tektronix P6015A, USA) and a current probe (Tektronix P6021, USA).

2.3. Adsorption Experiments. After the DBD plasma treatment, $0.05,0.1,0.2,0.3$, and $0.4 \mathrm{~g}$ of resins were added into the phenol solution $(50 \mathrm{~mL}, 100 \mathrm{mg} / \mathrm{L})$ in a series of sealed flasks. These flasks were placed in the water bath shaker with a $150 \mathrm{rpm}$ of agitation speed.

The concentrations of phenol were determined by a UVvis spectrophotometer (UV-2102C, Unico (Shanghai, China) Instrument Co., Ltd.). The equilibrium adsorption capacity of phenol onto the adsorbent $\left(q_{e}, \mathrm{mg} / \mathrm{g}\right)$ was calculated from the following equation:

$$
q_{e}=\left(C_{o}-C_{e}\right) \frac{V}{m}
$$

where $C_{o}$ and $C_{e}(\mathrm{mg} / \mathrm{L})$ are the initial and equilibrium concentration of phenol in solution, $q_{e}$ is the adsorption capacity of resin, $V(\mathrm{~L})$ is the volume of solution, and $m(\mathrm{~g})$ is the adsorbent mass.

Langmuir isotherm is used to describe a type of monolayer adsorption, which has a finite number of identical localized sites:

$$
q_{e}=\frac{Q_{o} K_{L} C_{e}}{1+K_{L} C_{e}},
$$

where $Q_{o}(\mathrm{mg} / \mathrm{g})$ is the initial amount of adsorbate and $K_{L}$ $(\mathrm{L} / \mathrm{g})$ is a Langmuir constant related to the affinity of the binding site.

Freundlich sorption isotherm is the most widely used equation describing the nonideal and reversible adsorption, and the equation has the form:

$$
q_{e}=K_{F} C_{e}^{1 / n}
$$


TABLE 1: Effect of applied voltage on adsorption kinetic parameters of virgin and DBD treated resins.

\begin{tabular}{|c|c|c|c|c|c|c|c|}
\hline \multirow{2}{*}{ Sample } & \multirow{2}{*}{$\operatorname{Exp} q_{e, \exp }(\mathrm{mg} / \mathrm{g})$} & \multicolumn{3}{|c|}{ Lagergren first-order } & \multicolumn{3}{|c|}{ Pseudo-second-order } \\
\hline & & $k_{1}(1 / \mathrm{h})$ & $q_{e, \mathrm{cal}}(\mathrm{mg} / \mathrm{g})$ & $R^{2}$ & $k_{2}(\mathrm{~g} / \mathrm{mg} / \mathrm{h})$ & $q_{e, \mathrm{cal}}(\mathrm{mg} / \mathrm{g})$ & $R^{2}$ \\
\hline Untreated & 112.4 & 0.510 & 102.3 & 0.923 & 0.002348 & 117.2 & 0.984 \\
\hline $16 \mathrm{kV}$ & 123.4 & 0.453 & 111.1 & 0.976 & 0.004471 & 126.4 & 0.995 \\
\hline $20 \mathrm{kV}$ & 133.1 & 0.443 & 124.2 & 0.961 & 0.004788 & 137.8 & 0.996 \\
\hline $24 \mathrm{kV}$ & 114.7 & 0.429 & 101.3 & 0.893 & 0.002669 & 117.8 & 0.988 \\
\hline $28 \mathrm{kV}$ & 109.0 & 0.461 & 94.5 & 0.942 & 0.002567 & 112.1 & 0.986 \\
\hline
\end{tabular}

TABLE 2: Effect of applied voltage on Freundlich and Langmuir parameters of virgin and DBD treated resins.

\begin{tabular}{lccccc}
\hline Adsorbents & \multicolumn{3}{c}{ Freundlich parameters } & \multicolumn{3}{c}{ Langmuir parameters } \\
& $1 / n$ & $K_{F}\left(\mathrm{mg}^{(1-1 / n)} \mathrm{L}^{1 / n} / \mathrm{g}\right)$ & $R^{2}$ & $q_{m}(\mathrm{mg} / \mathrm{g})$ & $K_{L}(\mathrm{~L} / \mathrm{mg})$ \\
\hline Untreated & 0.7681 & 1.966 & 0.977 & 115.3 & 0.01053 \\
$16 \mathrm{kV}$ & 0.7766 & 2.174 & 0.978 & 126.0 & 0.01106 \\
$20 \mathrm{kV}$ & 0.7778 & 2.318 & 0.989 & 133.8 & 0.926 \\
$24 \mathrm{kV}$ & 0.7736 & 2.035 & 0.980 & 119.0 & 0.936 \\
$28 \mathrm{kV}$ & 0.7913 & 1.581 & 0.986 & 114.0 & 0.0108 \\
\hline
\end{tabular}

where $K_{F}\left(\mathrm{mg}^{(1-1 / n)} \mathrm{L}^{1 / n} / \mathrm{g}\right)$ is a Freundlich constant related to adsorption amount and $n$ is also a Freundlich constant to measure the adsorption intensity.

For the purpose of comparison the adsorption capacity before and after DBD plasma treatment, the same method was used to determine the adsorption kinetic of the virgin resin.

2.4. Analysis Method. The surface characteristics of virgin and DBD treated resins were measured from the $\mathrm{N}_{2}$ adsorption at $77 \mathrm{~K}$ by NOVA 1200 (Quanta Chrome) equipment. Surface areas were identified according to the BET method. FTIR spectroscopy (EQUINOX5 spectrophotometer) was applied to characterize the chemical properties of the resin samples.

\section{Results and Discussion}

3.1. DBD Modified Resins Adsorption. In this study, the comparison of adsorption dynamics and isotherms of the resins has been done before and after DBD treatment under different operation parameters, including applied voltage, treatment time, and air flow rate, which allow us to obtain valuable information for the adsorption process of these resin samples.

Adsorption kinetic is an important physical characterization of adsorption rate, because it could indicate the removal rate of the pollutant in aqueous solutions and provide valuable data for a good understanding of the sorption reactions mechanism. Therefore, Lagergren first-order and pseudo-second-order kinetic models were utilized in the analysis of the experimental data in this study.

Analysis of isotherm data is very important for predicting adsorption capacity and adsorption behavior of adsorbent. Several models have appeared in the literature to evaluate adsorption isotherm. The Langmuir and Freundlich [15] models are the models often used. In the Langmuir model it is assumed that the adsorption is totally homogeneous in the surface of adsorbent, whereas it is a highly heterogeneous surface for Freundlich model. Thus, Langmuir and Freundlich isotherm models were tested and made the comparison of the goodness of fit based on the experimental data.

3.1.1. Effect of Applied Voltage. The strength of electric field obviously affects the generation of active species (such as $\mathrm{O}_{3}$, $\cdot \mathrm{OH}$, etc.) in DBD plasma and thus can influence the resin modification. The other viable run parameters were included below: treatment time $30 \mathrm{~min}$ and air flow rate $0.8 \mathrm{~L} / \mathrm{min}$. Figure 3 presented the adsorption kinetics of virgin and DBD treated resins under different applied voltages. For both samples, phenol adsorption was quick in the initial $7 \mathrm{~h}$, and the equilibrium plateau was achieved in $12 \mathrm{~h}$. After that time point, the adsorption amount kept constant.

The fast adsorption is probably because the pore structure of the resins offered sufficient available adsorption sites in the early stage of the adsorption. Thereafter the active sites reduced with increasing contact time, and then the observed plateau appeared.

Table 1 showed the kinetics of phenol adsorption on the resin samples. The Lagergren first-order and pseudo-secondorder models were used to investigate the adsorption mechanisms. Clearly, the correlation coefficients of the pseudosecond-order model were much closer to 1 , and the calculated $q_{e}$ accorded well with the experimental data, proving that this model could be adopted for the simulation of the resins adsorption to phenol.

The fitting results of the Freundlich and Langmuir models were presented in Table 2 and Figure 4. The contrasted results showed that the theoretical calculations of Freundlich model could be better fitted to the experimental data than Langmuir.

In summary, as shown in Figures 3 and 4 and Tables 1 and 2, the DBD treated resins adsorption capacities upgraded firstly and then decreased with the rising peak voltages. When the applied voltage was $20 \mathrm{kV}$, the optimal adsorption 
TABLE 3: Effect of treatment time on adsorption kinetic parameters of virgin and DBD treated resins.

\begin{tabular}{lcccccc}
\hline Sample & Exp $q_{e, \exp }(\mathrm{mg} / \mathrm{g})$ & $k_{1}(1 / \mathrm{h})$ & $\begin{array}{c}\text { Lagergren first-order } \\
q_{e, \text { cal }}(\mathrm{mg} / \mathrm{g})\end{array}$ & $R^{2}$ & $k_{2}(\mathrm{~g} / \mathrm{mg} / \mathrm{h})$ & \multicolumn{2}{c}{ Pseudo-second-order } \\
$q_{e, \text { cal }}(\mathrm{mg} / \mathrm{g})$
\end{tabular}

TABLE 4: Effect of applied voltage on Freundlich and Langmuir parameters of virgin and DBD treated resins.

\begin{tabular}{lccccc}
\hline \multirow{2}{*}{ Adsorbents } & \multicolumn{3}{c}{ Freundlich parameters } \\
& $1 / n$ & $K_{F}\left(\mathrm{mg}^{(1-1 / n)} \mathrm{L}^{1 / n} / \mathrm{g}\right)$ & $R^{2}$ & $q_{m}(\mathrm{mg} / \mathrm{g})$ & \multicolumn{2}{c}{ Langmuir parameters } \\
$K_{L}(\mathrm{~L} / \mathrm{mg})$ & 0.01053 \\
\hline Untreated & 0.7681 & 1.966 & 0.987 & 115.3 & 0.923 \\
$15 \mathrm{~min}$ & 0.7657 & 2.093 & 0.975 & 117.4 & 0.91107 \\
$30 \mathrm{~min}$ & 0.7778 & 2.318 & 0.982 & 133.8 & 0.01119 \\
$45 \mathrm{~min}$ & 0.7864 & 2.485 & 0.974 & 148.9 & 0.01103 \\
$60 \mathrm{~min}$ & 0.7599 & 1.822 & 0.982 & 106.5 & 0.01018 \\
\hline
\end{tabular}

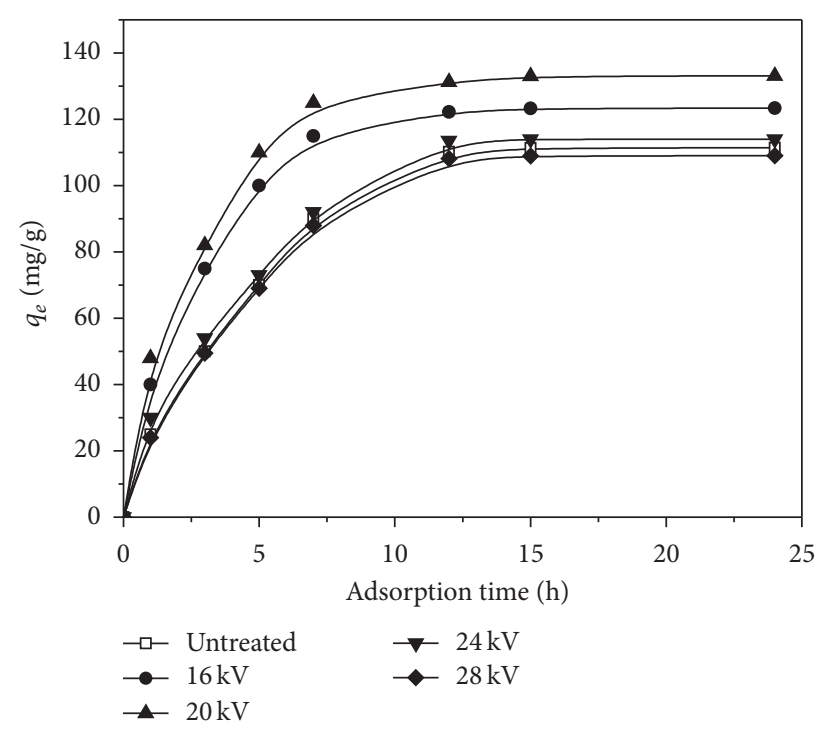

FIGURE 3: Effect of applied voltage on adsorption kinetics of virgin and DBD treated resins.

capability was $133.1 \mathrm{mg} / \mathrm{g}$ and increased $19.4 \%$ than untreated one. In contrast, the adsorption capability of $28 \mathrm{kV}$ was $109.0 \mathrm{mg} / \mathrm{g}$ and lower than virgin one. It is generally believed that the excessive voltage produces more active species in plasma, which could affect the surface properties of resins, resulting in the fact that their hydrophilicity was enhanced. Under this circumstance, it was helpful for the adsorption of resin for phenol. However, the energetic species could also collapse the adsorption channels and framework of resin under higher voltage, leading to the decline of adsorption capacity of resin.

3.1.2. Effect of Treatment Time. The DBD plasma treatment time would also directly affect the generation of active species

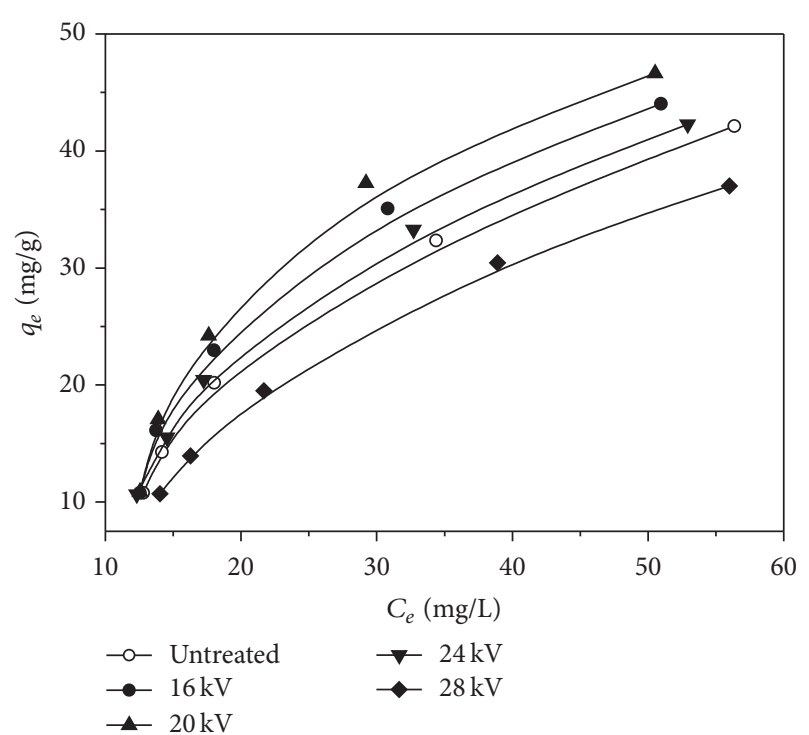

FIGURE 4: Effect of applied voltage on adsorption isotherm of virgin and DBD treated resins.

and the influence of the modification of the resins, so the effects of treatment time on resin adsorption should be clarified. The other practical run parameters included applied voltage $20 \mathrm{kV}$ and air flow rate $0.8 \mathrm{~L} / \mathrm{min}$. Figure 5 indicated the adsorption kinetics of virgin and DBD treated resins under different treatment times. Combining the determination coefficient in Table 3 , it is obvious that the pseudosecond-order model can imitate the phenol adsorption on resins more accurately than the Lagergren first-order.

The fitting results of the Freundlich and Langmuir isotherms were shown in Table 4 and Figure 6. By analysis and comparison, the Freundlich model could be better used to simulate the phenol adsorption onto virgin resin and $\mathrm{DBD}$ 
TABLE 5: Effect of air flow rate on adsorption kinetic parameters of virgin and DBD treated resins.

\begin{tabular}{|c|c|c|c|c|c|c|c|}
\hline \multirow{2}{*}{ Sample } & \multirow{2}{*}{$\operatorname{Exp} q_{e, \exp }(\mathrm{mg} / \mathrm{g})$} & \multicolumn{3}{|c|}{ Lagergren first-order } & \multicolumn{3}{|c|}{ Pseudo-second-order } \\
\hline & & $k_{1}(1 / \mathrm{h})$ & $q_{e, \mathrm{cal}}(\mathrm{mg} / \mathrm{g})$ & $R^{2}$ & $k_{2}(\mathrm{~g} / \mathrm{mg} / \mathrm{h})$ & $q_{e, \mathrm{cal}}(\mathrm{mg} / \mathrm{g})$ & $R^{2}$ \\
\hline Untreated & 112.4 & 0.510 & 102.3 & 0.923 & 0.002348 & 117.2 & 0.984 \\
\hline $0.4 \mathrm{~L} / \mathrm{min}$ & 111.4 & 0.454 & 101.7 & 0.937 & 0.002592 & 115.6 & 0.985 \\
\hline $0.8 \mathrm{~L} / \mathrm{min}$ & 145.8 & 0.430 & 134.5 & 0.877 & 0.005135 & 147.1 & 0.997 \\
\hline $1.2 \mathrm{~L} / \mathrm{min}$ & 156.5 & 0.410 & 144.9 & 0.984 & 0.004462 & 157.8 & 0.997 \\
\hline $1.6 \mathrm{~L} / \mathrm{min}$ & 127.1 & 0.387 & 117.4 & 0.931 & 0.002796 & 130.5 & 0.987 \\
\hline
\end{tabular}

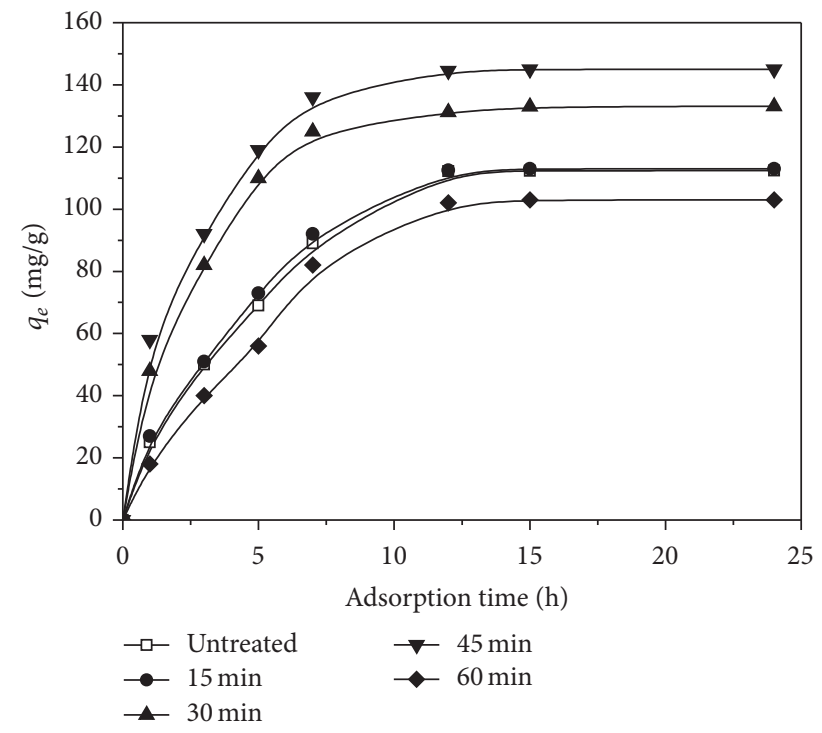

FIGURE 5: Effect of treatment time on adsorption kinetics of virgin and DBD treated resins.

treated resins under different treatment times than Langmuir model.

The adsorption quantity of phenol firstly rose and then decreased with increasing treatment time (as shown in Figure 5 and Table 3). When the discharge time increased to $45 \mathrm{~min}$, the corresponding adsorption amount was $145.8 \mathrm{mg}$ / g, which was enhanced to $29.0 \%$ compared to the untreated sample, whereas when discharge time extended to $60 \mathrm{~min}$, the adsorption capability was $8.4 \%$ lower than virgin one. This phenomenon may be attributed to the following reasons: the increase of the treatment time resulted in the increase in the collision and even reacting probabilities between the active species and the resin, which was favorable to enhance the variety of oxygen-containing functional groups on the resin surface, strengthening the electrostatic and hydrogen bonding interactions during the phenol adsorption process. On the contrary, prolonging the reaction time would oxidize the surface structure of resin, resulting in the fact that its textural structure collapses. So it could be suggested that a longer treatment time is harmful to the adsorption of resin.

3.1.3. Effect of Air Flow Rate. Gas source is essential for nonthermal plasma production. In this research, we employed air

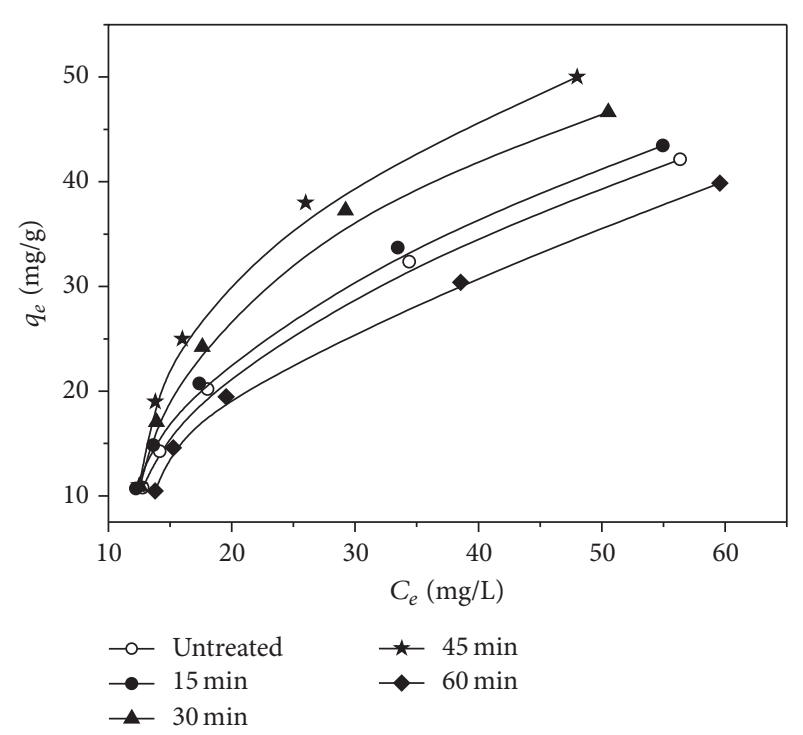

FIGURE 6: Effect of treatment time on adsorption isotherm of virgin and DBD treated resins.

as the gas source for the $\mathrm{DBD}$ reactor. Other experimental conditions included applied voltage $20 \mathrm{kV}$ and treatment time $45 \mathrm{~min}$.

Figure 7 shows the sorption kinetics of virgin and DBD treated resins under different air flow rates. Combining Table 5, it is obvious that the pseudo-second-order model has higher goodness of fit than the Lagergren first-order. Moreover, combining Figure 8 and Table 6, it can be inferred that the Freundlich model can fit better the phenol adsorption data for virgin resin and DBD treated resins.

From these figures and tables, it can be seen that the adsorption was increased with air flow rate. However, the improvement of the adsorption at $0.4 \mathrm{~L} / \mathrm{min}$ was not so promoted compared with the untreated one. The maximal adsorption was achieved $156.5 \mathrm{mg} / \mathrm{g}$ when air flow rate was $1.2 \mathrm{~L} / \mathrm{min}$, which was $39.2 \%$ higher than the untreated one. It could be suggested that, with the increase of air flow, the amount of active species produced by DBD plasma is increased, which is benefit to improve the surface chemical properties. Conversely, when the air flow rate is too high $(1.6 \mathrm{~L} / \mathrm{min})$, the residence time of active species in DBD reactor is shortened and their utilization efficiencies are correspondingly decreased. Hence, the combined effects of above 
TABLE 6: Effect of air flow rate on Freundlich and Langmuir parameters of virgin and DBD treated resins.

\begin{tabular}{lccccc}
\hline Adsorbents & \multicolumn{3}{c}{ Freundlich parameters } & \multicolumn{3}{c}{ Langmuir parameters } \\
& $1 / n$ & $K_{F}\left(\mathrm{mg}^{(1-1 / n)} \mathrm{L}^{1 / n} / \mathrm{g}\right)$ & $R^{2}$ & $q_{m}(\mathrm{mg} / \mathrm{g})$ & $K_{L}(\mathrm{~L} / \mathrm{mg})$ \\
\hline Untreated & 0.7681 & 1.966 & 0.977 & 115.3 & 0.01053 \\
$0.4 \mathrm{~L} / \mathrm{min}$ & 0.7597 & 2.123 & 0.974 & 114.2 & 0.01140 \\
$0.8 \mathrm{~L} / \mathrm{min}$ & 0.7864 & 2.485 & 0.964 & 148.9 & 0.91103 \\
$1.2 \mathrm{~L} / \mathrm{min}$ & 0.7918 & 2.574 & 0.953 & 156.1 & 0.924 \\
$1.6 \mathrm{~L} / \mathrm{min}$ & 0.7549 & 2.615 & 0.965 & 127.2 & 0.909 \\
\end{tabular}

TABLE 7: Structural properties of the virgin and DBD treated resin.

\begin{tabular}{lccccc}
\hline Resin samples & $S_{\text {BET }}\left(\mathrm{m}^{2} / \mathrm{g}\right)$ & $S_{\text {Micropore }}\left(\mathrm{m}^{2} / \mathrm{g}\right)$ & $V_{\text {Micropore }}\left(\mathrm{m}^{3} / \mathrm{g}\right)$ & $V_{\text {Total pore }}\left(\mathrm{m}^{3} / \mathrm{g}\right)$ & Average pore diameter $(\mathrm{nm})$ \\
\hline Untreated & 944.6 & 715.8 & 0.377 & 0.586 & 1.428 \\
DBD 1 & 1056.4 & 838.9 & 0.593 & 0.658 & 1.428 \\
DBD 2 & 937.7 & 605.1 & 0.301 & 0.610 & 1.418 \\
\hline
\end{tabular}

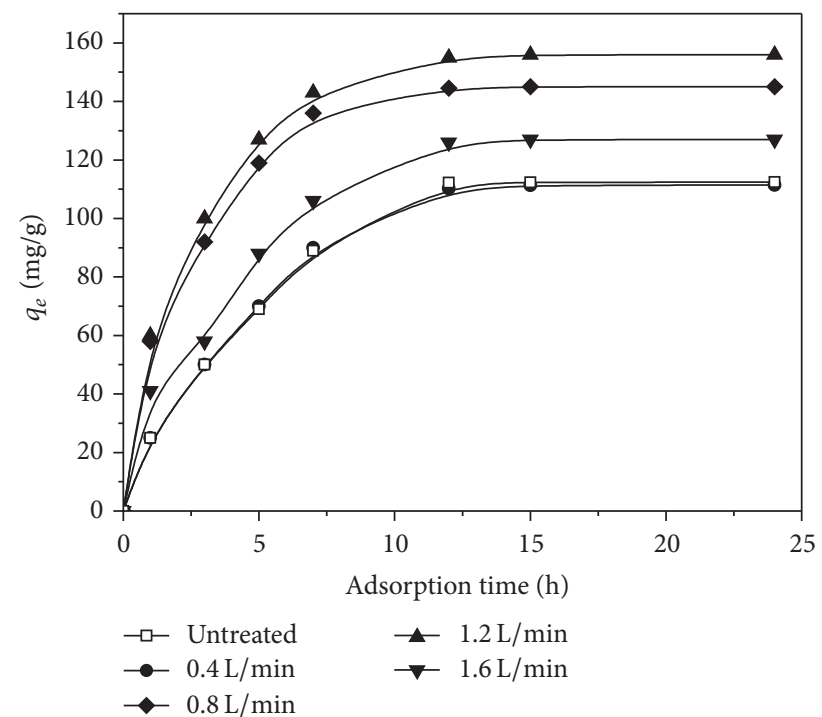

FIGURE 7: Effect of air flow rate on adsorption kinetics of virgin and DBD treated resins.

two aspects resulted in the best adsorption performance achieved when the air flow rate was $1.2 \mathrm{~L} / \mathrm{min}$.

3.2. FTIR Spectra Analysis. Figure 9 illustrates the FTIR spectra obtained from the virgin and DBD plasma treated resins. The sample presenting the highest adsorption capacity, which was treated under the condition of applied voltage $20 \mathrm{kV}$, treatment time $45 \mathrm{~min}$, and air flow rate $1.2 \mathrm{~L} / \mathrm{min}$, was named as DBD 1. In contrast, DBD 2 was the lowest result at applied voltage $20 \mathrm{kV}$, treatment time $60 \mathrm{~min}$, and air flow rate $0.8 \mathrm{~L} / \mathrm{min}$. From Figure 9, DBD 1 and DBD 2 had two strong representative peaks at 1604 and $2922 \mathrm{~cm}^{-1}$ similar to untreated one but were both greatly weakened. DBD also results in some new changes for the IR spectrum of treated samples. Firstly, a moderate $\mathrm{C}-\mathrm{O}$ stretching band involving hydroxyl groups came back at $1105 \mathrm{~cm}^{-1}$, and appearance of

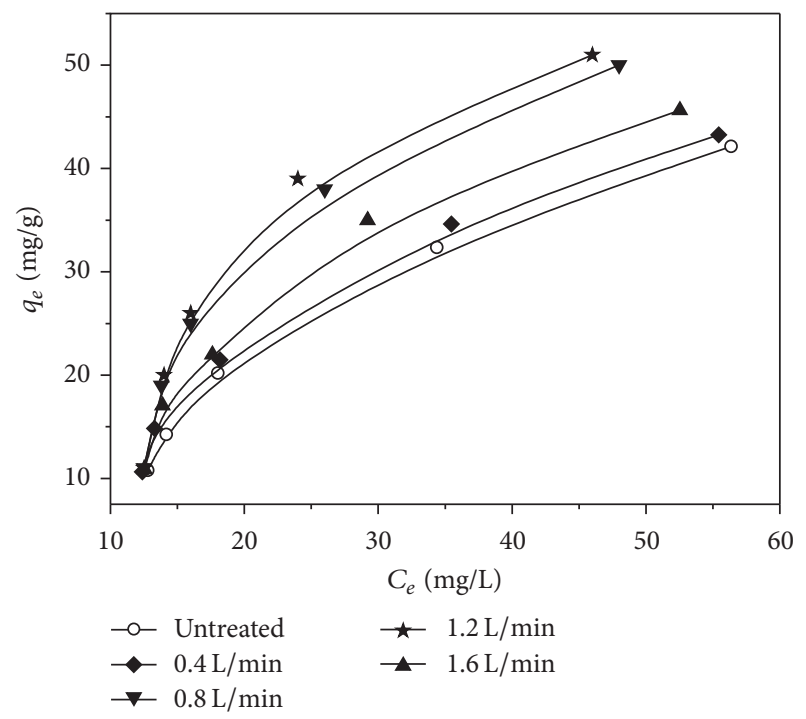

FIGURE 8: Effect of air flow rate on adsorption isotherm of virgin and DBD treated resins.

this band might result from DBD treatment [16]. Secondly, the peak at $3600 \mathrm{~cm}^{-1}$ disappeared through DBD treatment, which could be assigned to $\mathrm{O}-\mathrm{H}[4]$.

3.3. Surface Textural Properties. Table 7 mainly generalized the relevant surface structural properties of virgin and DBD treated resin. Based on the information observed in Table 7 , it could be noticed that the various data of the DBD treated samples were considerable different from the virgin one. Compared with the untreated resin, DBD 1 resin had a bigger BET surface area, micropore area, micropore volume, and total pore volume. Conversely, all data of DBD 2 has little change compared to the virgin resin. It can be indicated that the surface area and pore volume of DBD 1 were upgraded by the suitable plasma treatment. It is generally believed that the surface textural properties of resin were improved under conditions of DBD 1; at the same time, along with the DBD 


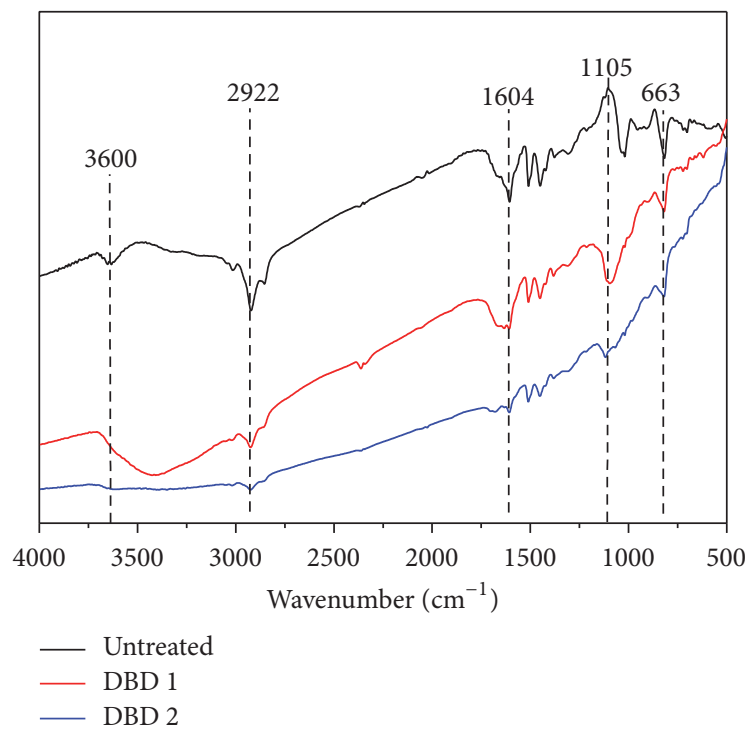

FIGURE 9: FTIR spectra of untreated and DBD treated resin.

chemical effects, such as electrostatic and hydrogen bonding interactions, the enhancement of adsorption capacity reached.

\section{Conclusions}

The DBD treatment for surface modification of macroporous resin had been performed for improving its adsorbability for phenol. Significant influences of applied voltage, treatment time, and air flow rate on resin adsorption capacity were observed. The experimental results show that the adsorbability of DBD treated resin was $156.5 \mathrm{mg} / \mathrm{g}$ and $39.2 \%$ higher than the untreated resin when the treatment was conducted in these conditions, such as discharge voltage $20 \mathrm{kV}$, treatment time $45 \mathrm{~min}$, and air flow rate $1.2 \mathrm{~L} / \mathrm{min}$. The phenol adsorption on resins was fitted well with the pseudo-second-order and Freundlich model, indicating the homogeneity of the resin surface. At the optimum conditions, the DBD treatment increased the surface area and pore volume of the resin but slightly changed the surface chemical properties. The obtained experimental data has demonstrated that the DBD could enhance the phenol adsorption of resin effectively.

\section{Competing Interests}

The authors declare that there is no conflict of interests regarding the publication of this paper.

\section{Acknowledgments}

The authors acknowledge the financial support supplied by the Natural Science Foundation of Hebei Province, China (Project nos. B2015203303 and B2015203300), the China Postdoctoral Science Foundation (Project no. 2015M580216), the Youth Teacher Independent Research Program of Yanshan University (Project nos. 15LGA013 and 14LGB021), and the Doctoral Foundation Program of Yanshan University (Project nos. B849 and B878).

\section{References}

[1] S.-H. Lin and R.-S. Juang, "Adsorption of phenol and its derivatives from water using synthetic resins and low-cost natural adsorbents: a review," Journal of Environmental Management, vol. 90, no. 3, pp. 1336-1349, 2009.

[2] I. Turku and T. Sainio, "Modeling of adsorptive removal of benzalkonium chloride from water with a polymeric adsorbent," Separation and Purification Technology, vol. 69, no. 2, pp. 185194, 2009.

[3] G. Li, X. Wei, W. Wang, T. He, and X. Li, "Modification of unsaturated polyester resins (UP) and reinforced UP resins via plasma treatment," Applied Surface Science, vol. 257, no. 1, pp. 290-295, 2010.

[4] X. Wang, J. Huang, and K. Huang, "Surface chemical modification on hyper-cross-linked resin by hydrophilic carbonyl and hydroxyl groups to be employed as a polymeric adsorbent for adsorption of p-aminobenzoic acid from aqueous solution," Chemical Engineering Journal, vol. 162, no. 1, pp. 158-163, 2010.

[5] T. Acsente, M. D. Ionita, M. Teodorescu, V. Marascu, and G. Dinescu, "Surface modification of polymethylmethacrylate foils using an atmospheric pressure plasma jet in presence of water vapors," Thin Solid Films, vol. 614, pp. 25-30, 2016.

[6] K. Chen, H. Lyu, S. Hao, G. Luo, S. Zhang, and J. Chen, "Separation of phenolic compounds with modified adsorption resin from aqueous phase products of hydrothermal liquefaction of rice straw," Bioresource Technology, vol. 182, pp. 160-168, 2015.

[7] J. Huang, L. Yang, X. Wu, M. Xu, Y.-N. Liu, and S. Deng, "Phenol adsorption on $\alpha, \alpha /$-dichloro-p-xylene (DCX) and 4,4/bis(chloromethyl)-1,1/-biphenyl (BCMBP) modified XAD-4 resins from aqueous solutions," Chemical Engineering Journal, vol. 222, pp. 1-8, 2013.

[8] L. Karam, M. Casetta, N. E. Chihib, F. Bentiss, U. Maschke, and C. Jama, "Optimization of cold nitrogen plasma surface modification process for setting up antimicrobial low density polyethylene films," Journal of the Taiwan Institute of Chemical Engineers, vol. 64, pp. 299-305, 2016.

[9] Q. Li, H. Lu, H. Xiao, K. Gao, and M. Diao, "Adsorption capacity of superabsorbent resin composite enhanced by non-thermal plasma and its adsorption kinetics and isotherms to lead ion in water," Journal of Environmental Chemical Engineering, vol. 1, no. 4, pp. 996-1003, 2013.

[10] S. Kodama, H. Habaki, H. Sekiguchi, and J. Kawasaki, "Surface modification of adsorbents by dielectric barrier discharge," Thin Solid Films, vol. 407, no. 1-2, pp. 151-155, 2002.

[11] S. Marais, M. Métayer, M. Labbé et al., "Surface modification by low-pressure glow discharge plasma of an unsaturated polyester resin: effect on water diffusivity and permeability," Surface and Coatings Technology, vol. 122, no. 2-3, pp. 247-259, 1999.

[12] L. Xin, Y. Sun, J. Feng, J. Wang, and D. He, "Degradation of triclosan in aqueous solution by dielectric barrier discharge plasma combined with activated carbon fibers," Chemosphere, vol. 144, pp. 855-863, 2016.

[13] C. A. Aggelopoulos, P. Svarnas, M. I. Klapa, and C. D. Tsakiroglou, "Dielectric barrier discharge plasma used as a means for the remediation of soils contaminated by non-aqueous phase liquids," Chemical Engineering Journal, vol. 270, pp. 428-436, 2015. 
[14] S. Tang, N. Lu, J. Li, K. Shang, and Y. Wu, "Improved phenol decomposition and simultaneous regeneration of granular activated carbon by the addition of a titanium dioxide catalyst under a dielectric barrier discharge plasma," Carbon, vol. 53, pp. 380-390, 2013.

[15] B. J. Pan, B. C. Pan, W. M. Zhang, L. Lv, Q. X. Zhang, and S. R. Zheng, "Development of polymeric and polymer-based hybrid adsorbents for pollutants removal from waters," Chemical Engineering Journal, vol. 151, no. 1-3, pp. 19-29, 2009.

[16] G. C. Pratt, C. Y. Wu, D. Bock et al., "Comparing air dispersion model predictions with measured concentrations of VOCs in urban communities," Environmental Science and Technology, vol. 38, no. 7, pp. 1949-1959, 2004. 

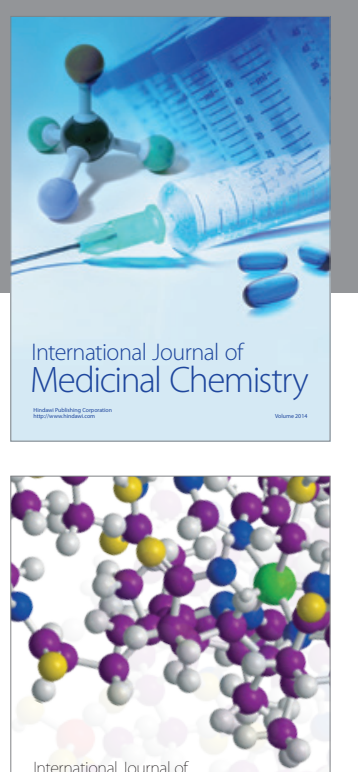

Carbohydrate Chemistry

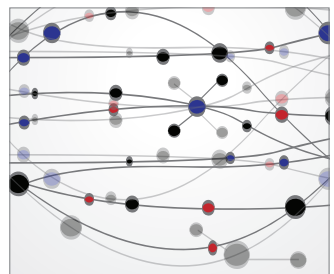

The Scientific World Journal
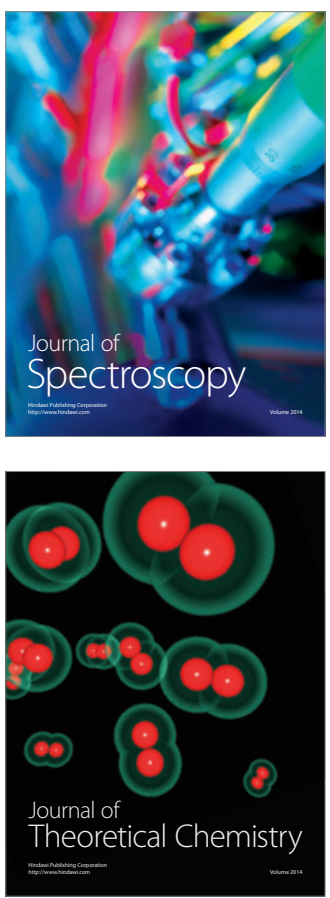
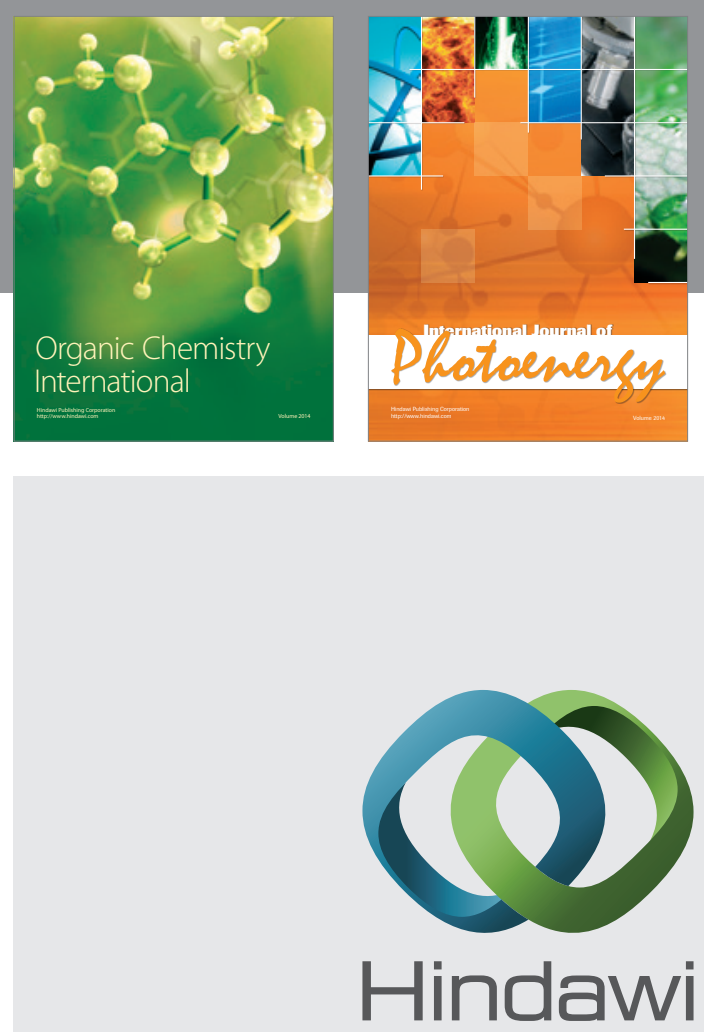

Submit your manuscripts at

http://www.hindawi.com

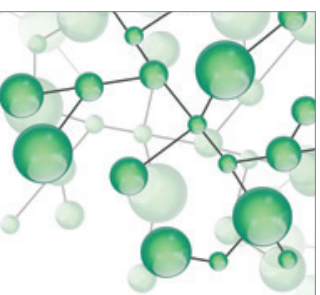

International Journal of

Inorganic Chemistry

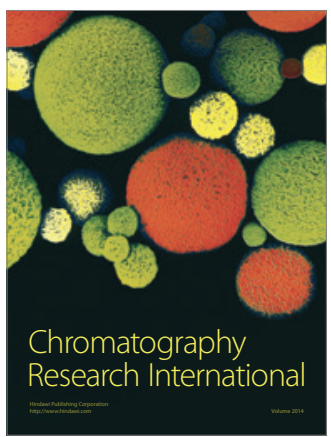

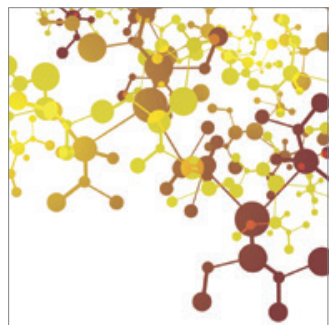

Applied Chemistry
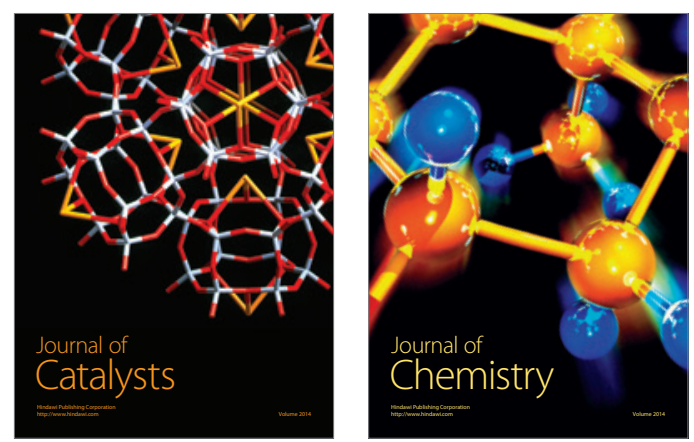
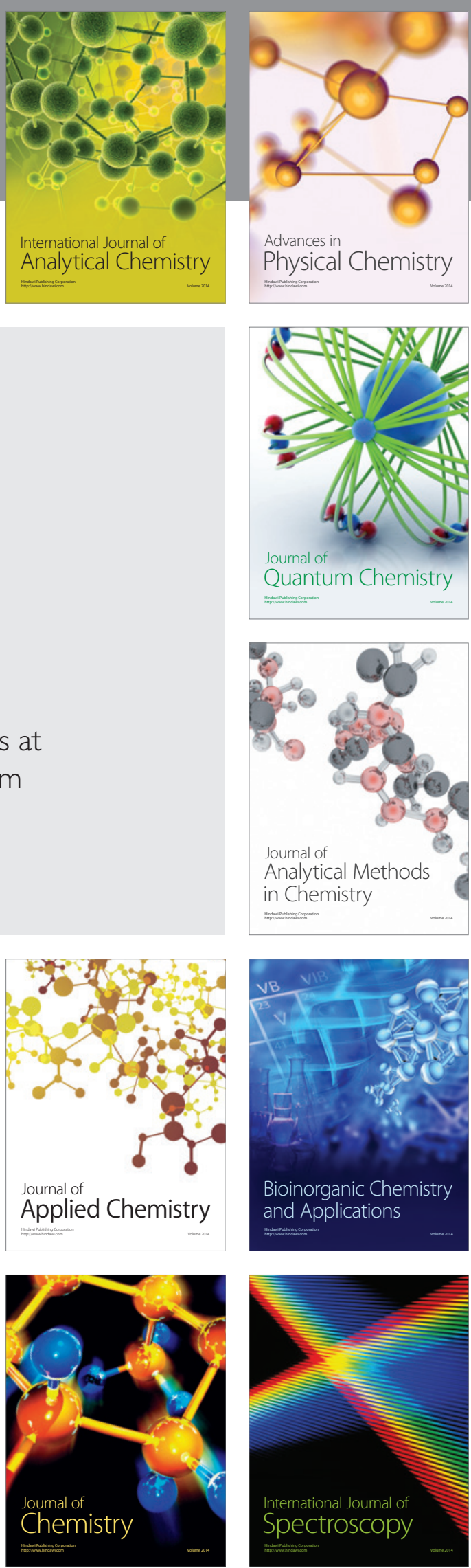